\title{
Ipsilateral coordination at preferred rate: Effects of age, body side and task complexity
}

\author{
Annouchka Van Impe, James P. Coxon, Daniel J. Goble, Nici Wenderoth, Stephan Patrick Swinnen * \\ Laboratory of Motor Control, Research Center for Motor Control and Neuroplasticity, Group Biomedical Sciences, K.U.Leuven, Tervuursevest 101, B-3001 Heverlee, Belgium
}

\section{A R T I C L E I N F O}

\section{Article history:}

Received 20 March 2009

Revised 10 June 2009

Accepted 11 June 2009

Available online 17 June 2009

\section{Keywords:}

Aging

fMRI

Motor control

Interlimb coordination

Task complexity

Body side

\begin{abstract}
A B S T R A C T
Functional imaging studies have shown that elderly individuals activate widespread additional brain networks, compared to young subjects, when performing motor tasks. However, the parameters that effect this unique neural activation, including the spatial distribution of this activation across hemispheres, are still largely unknown. Here, we examined the effect of task complexity and body side on activation differences between older and younger adults while performing cyclical flexion-extension movements of the ipsilateral hand and foot. In particular, easy (isodirectional) and more difficult (non-isodirectional) coordination patterns were performed with either the left or right body side at a self-selected, comfortable rate. Even in the absence of imposed pacing the older group activated a larger brain network, suggestive of increased attentional deployment for monitoring the spatial relationships between the simultaneously moving segments and enhanced sensory processing and integration. Evidence of age-dependent underactivation was also found in contralateral M1, SMA and bilateral putamen, possibly reflecting a functional decline of the basal ganglia-mesial cortex pathway in the older group. An ANOVA model revealed significant main effects of task complexity and body side. However the interaction of these factors with age did not reach significance. Consequently, we conclude that under self-paced conditions, task complexity and body side did not have a modulatory effect on age-related brain activation.
\end{abstract}

(c) 2009 Elsevier Inc. All rights reserved.

\section{Introduction}

Healthy aging is characterized by neuroanatomical (Good et al., 2001; Sullivan and Pfefferbaum, 2006) and neurochemical changes (Volkow et al., 1998). This has implications not only for cognitive performance (Reuter-Lorenz and Lustig, 2005), but also for general motor ability. Indeed, movement slowing and increased variability of motor performance are some of the most prominent changes associated with the aging process (Spirduso and MacRae, 1990).

In addition, functional magnetic resonance imaging (fMRI) work has shown alterations in brain activity, as measured by the blood oxygenation level dependent (BOLD)-response (Cabeza et al., 2005; Ward, 2006). Age-related increases in brain activation, either overactivations in regions recruited by young subjects or unique, additional activations, have been observed, even for simple unilateral motor tasks. In some cases, these activations have been linked with more successful performance (Heuninckx et al., 2008; Ward, 2006). Whereas some have primarily observed increases in the hemisphere contralateral to the moving limb (Heuninckx et al., 2008), others have shown additional recruitment of sensorimotor and premotor regions ipsilateral to the moving limb (Calautti et al., 2001; Hutchinson et al., 2002; Mattay et al., 2002; Naccarato et al., 2006; Riecker et al., 2006; Rowe et al., 2006). This bilateral activation pattern is consistent with

\footnotetext{
* Corresponding author. Fax: +32 16329197.

E-mail address: Stephan.Swinnen@faber.kuleuven.be (S.P. Swinnen).
}

the HAROLD (Hemispheric Asymmetry Reduction in Old Age) model of aging, originally formulated from age-related memory research (Cabeza, 2002).

In healthy adolescents, increased neural (also ipsilateral) recruitment is usually observed only when tasks become more complex (Verstynen et al., 2005) or when movements are made with nondominant as compared to dominant limb segments (Kapreli et al., 2006; Kim et al., 1993; Mattay et al., 1998; Nirkko et al., 2001; Rogers et al., 2004). In view of this evidence for a modulatory effect of body side and task complexity on the degree and distribution of brain activation in adolescents, one is prompted to ask how these factors influence brain activation in elderly and, more generally, what are the boundary conditions for increased activation? Nevertheless, few studies have tested their impact on neural activity in older groups. Some have studied non-dominant limb movements in the elderly, using relatively simple motor tasks (Calautti et al., 2001; Hutchinson et al., 2002; Ward et al., 2008; Ward and Frackowiak, 2003). In this case, Calautti et al. (2001) found no differences in brain activation between young and old adults when moving their left index finger, whereas Hutchinson et al. (2002) found higher activations in bilateral supplementary motor area (SMA), caudate and thalamus in the elderly. Ward and Frackowiak (2003) and Ward et al. (2008), found a significant positive correlation between age ${ }^{2}$ and the BOLD-signal in ipsilateral M1, irrespective of the hand moved.

The impact of task complexity on brain activity in the context of aging was studied by Heuninckx et al. (2005). Participants performed metronome paced ipsilateral cyclical movements, with the right hand 
and foot moving in the same (isodirectional, ISO) versus different direction (non-isodirectional, NON-ISO). Even though a more extensive activation pattern was observed in the aged as compared to the young group during both coordination modes, the effects were more pronounced for the NON-ISO coordination condition. Specifically, prefrontal cortex (including dorsolateral prefrontal cortex (DLPFC)), pre-SMA, anterior cingulate cortex, precentral, parietal, and occipital regions, as well as cerebellum, were more activated during NON-ISO than during ISO coordination.

In the present study, we investigated age-related differences in neural recruitment as a function of body side and movement complexity during coordination of the ipsilateral hand and foot. First, we tested whether increased activation (or underactivation) was observed in the elderly as compared to the young group when participants were allowed to perform the coordination patterns at their individualized preferred speed (comfort pace). Previous work in this area imposed a movement frequency above comfort rate, resulting in age-related activation of areas associated with cognitive task involvement, sensory processing and intersensory integration (Heuninckx et al., 2005, 2008).

Second, brain activation differences during performance with the non-dominant versus dominant body side were tested. Based on the above mentioned studies in adolescents, it was hypothesized that increased (bilateral) activation in the aged group would be more pronounced during movements of the non-dominant as compared to the dominant body side. Third, differences in brain activation were studied as a function of coordination complexity by comparing the neural activations of NON-ISO versus ISO movements. Based on previous work (Heuninckx et al., 2005), it was hypothesized that age-related activation differences would be most prominent during the task conditions with the greatest demands, i.e., when performing NON-ISO coordination with the non-dominant body side (an "age $\times$ body side $\times$ coordination pattern" interaction).

\section{Methods}

\section{Subjects}

Seventeen young adults (mean age, 23.8 years, range 19-30) and 21 older adults (mean age 70.3 years, range 62-80) with no history of neurological diseases participated in the study. Scans of 2 seniors contained artifacts and were excluded from all analyses. The older subjects were all community dwelling individuals. The CHAMPS questionnaire (Community Healthy Activities Model Program for Seniors) (Stewart et al., 2001) was used to calculate their average amount of physical activity (kcal/week). All but 2 seniors used over $2900 \mathrm{kcal} /$ week and were thereby classified as being active seniors. All participants were right-handed and right-footed, as assessed by an adapted version of the Edinburgh Handedness Inventory (Oldfield, 1971). The Mini-mental state examination (Folstein et al., 1975) was used to determine general cognitive function, with all elderly scoring within normal limits (score $\geq 27$ ). Participants were informed about the experimental procedures and provided written informed consent. The study was approved by the local Ethics Committee of K.U.Leuven and was performed in accordance with the 1964 Declaration of Helsinki.

\section{Experimental design}

\section{Task}

An fMRI block design was utilized whereby participants performed 2 movement conditions and 1 condition during which no movements were performed (REST). The movement conditions required cyclical coordination of the ipsilateral hand and foot according to ISO or NONISO modes, while keeping the contralateral body side still (see Fig. 1). During ISO coordination, both limb segments moved in the same direction (i.e., hand flexion combined with foot plantar flexion). During NON-ISO coordination, the limb segments moved in opposite directions (i.e., hand flexion combined with foot dorsiflexion). Right and left body sides were examined in separate runs. Difficulty levels between groups were matched by performing the coordination tasks at a self-preferred movement frequency and amplitude. However, participants were instructed and trained to maintain a single rhythm over their respective movement conditions. To ensure correct performance, participants completed a practice session in a dummyscanner within $48 \mathrm{~h}$ of the experiment.

\section{Scanner set-up}

Participants lay supine in the scanner, with forearms pronated. To enable free wrist and ankle rotations, the forearms and legs were supported by cushions. The wrists and feet were positioned in nonferromagnetic orthoses, enabling on-line registration of movements during scanning and allowing the experimenters to check for possible mirror movements. High-precision shaft encoders (4096 pulses per revolution; sampled at $100 \mathrm{~Hz}$ ) fixed to the movement axis of the orthoses were used to register angular displacement of the joints. Subjects looked at a display via a mirror that was fixed to the head coil. Visual templates, instructing the task to be performed were projected onto the display by means of a Barco (Kortrijk, Belgium) 6400i liquid crystal display projector $(1024 \times 768$ pixels, $60 \mathrm{~Hz})$. A bite-bar was used to minimize head movements.

\section{fMRI data acquisition}

All scanning was performed on a $3 \mathrm{~T}$ Intera MR scanner (Philips, Best, The Netherlands), using a 6-element SENSE head coil (MRI Devices, Waukesha, WI). Six functional time series were acquired, each consisting of 105 whole brain gradient-echo echoplanar images (EPI) $(\mathrm{TR} / \mathrm{TE}=3000 / 33 \mathrm{~ms}$, field of view $=230 \mathrm{~mm}$, matrix $=112 \times 112$, slice thickness $=4.0 \mathrm{~mm}$, interslice gap $=0.4 \mathrm{~mm}, 34$ sagittal slices, SENSE factor $=2$ ). Each time series consisted of 5 blocks of the ISO, NON-ISO and REST conditions, with the order of the conditions balanced across runs. Three time series were performed with each body side and the order was counterbalanced across participants.

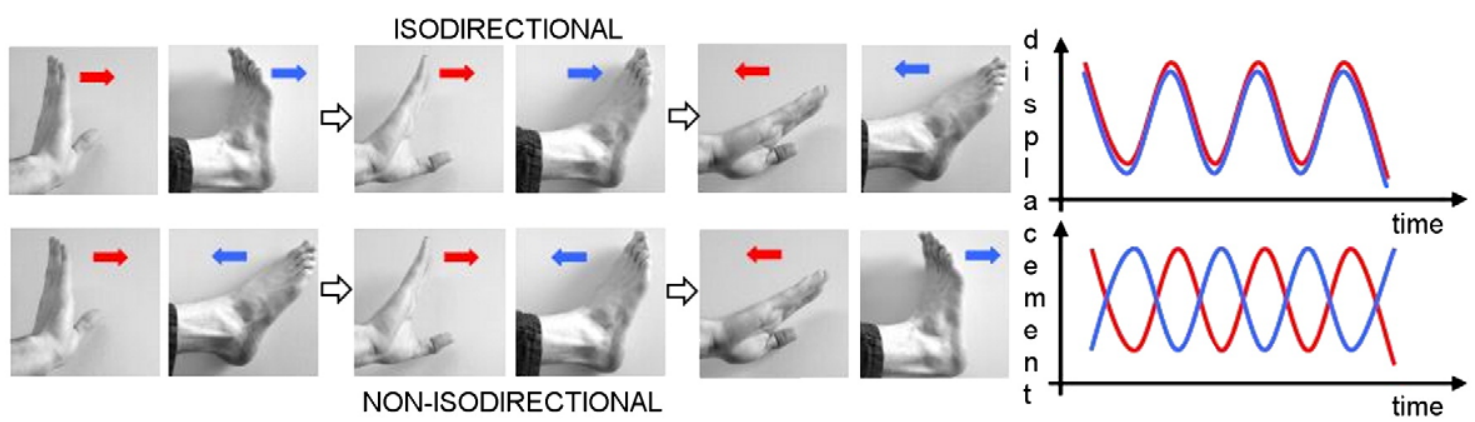

Fig. 1. Cyclical ipsilateral coordination according to the ISO (top panel) and NON-ISO (bottom panel) mode. 
Between the 6 time series, 2 min rest periods were provided to avoid muscle fatigue. Each scanning session ended with the acquisition of a 3D SENSE high resolution T1-weighted image (TR/TE =9.4/4.6 ms, $\mathrm{TI}=1100 \mathrm{~ms}$, field of view $=250 \mathrm{~mm}$, matrix $256 \times 256$, slice thickness $=1.2 \mathrm{~mm}$, 182 slices SENSE factor $=2$ ) for anatomical detail.

\section{Data analyses}

\section{Kinematic analysis}

Relative phase, i.e. the subtraction of the phase angles of each limb at each time point, was calculated according to the formula:

$\varphi=\theta_{\mathrm{w}}-\theta_{\mathrm{f}}=\tan ^{-1}\left[\left(\mathrm{~d} X_{\mathrm{w}} / \mathrm{d} t\right) / X_{\mathrm{w}}\right]-\tan ^{-1}\left[\left(\mathrm{~d} X_{\mathrm{f}} / \mathrm{d} t\right) / X_{\mathrm{f}}\right]$

(adapted from Kelso et al., 1986), whereby $w$ and $f$ refer to wrist and foot, respectively; $\theta$ is the mean phase of the limb at each point in the movement cycle, $X$ is the position of the limb after rescaling to the interval $[1,-1]$, and $\mathrm{d} X / \mathrm{d} t$ is the normalized instantaneous velocity. Absolute deviations from the target relative phase (i.e. $0^{\circ}$ for ISO and $180^{\circ}$ for NON-ISO coordination) were calculated to obtain a measure of interlimb coordination accuracy ( $\mathrm{AE}$, phase error). The standard deviation (SD) of the relative phase was used as a measure for variability or stability of coordination.

In addition, mean cycling frequency and amplitude (averaged across limbs) were calculated. Mean frequency was defined as the average frequency across individual movement cycles. The movement amplitude consisted of the absolute peak-to-peak amplitude for wrist and foot across individual movement cycles.

Prior to statistical analyses, the aforementioned parameters were determined for each condition and subsequently averaged across repetitions and runs. Statistical analyses then consisted of repeated measures analyses of variance (ANOVA) with between-subjects factor age (young, old) and the within-subjects factors mode (ISO, NON-ISO) and body side (non-dominant, dominant). The level of significance was set to $\alpha=0,05$. Post-hoc Tukey tests were performed for significant interactions.

\section{Imaging analysis}

SPM5, (Wellcome Department of Imaging Neuroscience, London, UK), implemented in Matlab 7.4 (Mathworks, Natick, MA), was used to analyze the imaging data. For each subject, all EPI scans were realigned to the first scan of the first time series in order to correct for interscan movements, and a mean image of the realigned volumes was created. To remove variance due to unwanted head movements that might have been task-related, images were unwarped (Andersson et al., 2001). Additionally, movement parameters derived from realignment were included as covariates of no interest to further correct for head movements. The mean image was smoothed with an isotropic Gaussian kernel of $6 \mathrm{~mm}$ full width at half maximum (FWHM) and normalized to a symmetrical EPI template. This symmetrical EPI template was the average of the standard EPI template (the Montreal Neurological Institute (MNI) reference brain in Talairach space) and its mirror image. The derived normalization parameters were then applied to the EPI images. Subsequently the EPI scans were resampled to a voxel size of $2 \times 2 \times 2 \mathrm{~mm}$ and smoothed with an isotropic Gaussian kernel of $10 \mathrm{~mm}$ FWHM.

All statistical analyses were performed in the context of the general linear model (Friston et al., 1995a,b) and each condition was modeled using a boxcar function convolved with the SPM hemodynamic response function. A $1 / 126 \mathrm{~Hz}$ high pass filter was applied to remove low frequency noise. To account for temporal autocorrelations an autoregressive AR(1) model was fit to the residuals of the fMRI times series. For each subject, movement conditions were contrasted with rest (averaging across repetitions and runs). These contrasts were then subjected to a second-level random-effects analysis.

\section{Second level analysis}

A full factorial ANOVA model was used, with age group (old vs. young) as between-subjects factor and coordination pattern (ISO vs. NON-ISO) and body side (dominant vs. non-dominant) as withinsubjects factors.

To compare ipsilateral and contralateral brain activations for left and right limb movements, the first-level contrast images for movements with the dominant body side were flipped about the midsaggital plane, according to the method described by Ward and Frackowiak (2003). The flipped contrast images were resliced to the original contrasts to correct for small shifts that could occur after flipping. Because all participants were allowed to move at their preferred rate and amplitude, movement frequency measures for all subjects (centered to the overall mean) were entered into the model as a covariate. The general movement network across all conditions was determined using an F-contrast, $(p<0.05$ corrected according to the false discovery rate (FDR), $F_{(10,134)} \geq 2.12$ ), and was subsequently used as an inclusive mask. Non-sphericity correction was applied when appropriate. The following t-contrasts were generated: 1) old vs. young, 2) young vs. old, 3) non-dominant vs. dominant body side movements, 4) dominant vs. non-dominant body side movements, 5) NON-ISO vs. ISO, 6) ISO vs. NON-ISO, 7) "age group $\times$ body side" interaction, 8) "age group $\times$ coordination pattern" interaction, 9) "age group $\times$ body side $\times$ coordination pattern" interaction. All statistical parametric maps ( $\operatorname{SPM}\{\mathrm{t}\}$ ) were thresholded at $p<0.05$, FDR corrected for multiple comparisons. Minimum cluster size was set at 30 voxels. Anatomical labels were ascribed to the activation maxima using the Anatomy toolbox (Eickhoff et al., 2005) and the atlas of Duvernoy (1999).

Table 1

Kinematic data.

\begin{tabular}{|c|c|c|c|c|}
\hline & \multicolumn{2}{|l|}{ Young } & \multicolumn{2}{|l|}{ Old } \\
\hline & ISO & NON-ISO & ISO & NON-ISO \\
\hline \multicolumn{5}{|c|}{ Left body side } \\
\hline Phase $\mathrm{AE}$ & $17.51^{\circ}\left(4.50^{\circ}\right)$ & $17.36^{\circ}\left(4.92^{\circ}\right)$ & $17.12^{\circ}\left(5.28^{\circ}\right)$ & $18.96^{\circ}\left(6.27^{\circ}\right)$ \\
\hline Phase SD & $20.42^{\circ}\left(2.85^{\circ}\right)$ & $21.89^{\circ}\left(6.09^{\circ}\right)$ & $19.37^{\circ}\left(3.85^{\circ}\right)$ & $25.59^{\circ}\left(8.38^{\circ}\right)$ \\
\hline Amplitude & $24.72^{\circ}\left(7.94^{\circ}\right)$ & $25.63^{\circ}\left(8.34^{\circ}\right)$ & $37.14^{\circ}\left(6.25^{\circ}\right)$ & $39.42^{\circ}\left(7.13^{\circ}\right)$ \\
\hline Frequency & $0.81 \mathrm{~Hz}(0.21 \mathrm{~Hz})$ & $0.8 \mathrm{~Hz}(0.21 \mathrm{~Hz})$ & $0.63 \mathrm{~Hz}(0.14 \mathrm{~Hz})$ & $0.64 \mathrm{~Hz}(0.16 \mathrm{~Hz})$ \\
\hline \multicolumn{5}{|c|}{ Right body side } \\
\hline Phase $\mathrm{AE}$ & $15.96^{\circ}\left(3.14^{\circ}\right)$ & $17.49^{\circ}\left(4.20^{\circ}\right)$ & $17.33^{\circ}\left(6.99^{\circ}\right)$ & $19.76^{\circ}\left(6.31^{\circ}\right)$ \\
\hline Phase SD & $19.54^{\circ}\left(1.79^{\circ}\right)$ & $22.66^{\circ}\left(5.71^{\circ}\right)$ & $18.60^{\circ}\left(3.21^{\circ}\right)$ & $25.54^{\circ}\left(6.01^{\circ}\right)$ \\
\hline Amplitude & $23.62^{\circ}\left(7.15^{\circ}\right)$ & $24.37^{\circ}\left(7.23^{\circ}\right)$ & $35.51^{\circ}\left(5.53^{\circ}\right)$ & $36.50^{\circ}\left(5.77^{\circ}\right)$ \\
\hline Frequency & $0.80 \mathrm{~Hz}(0.21 \mathrm{~Hz})$ & $0.81 \mathrm{~Hz}(0.20 \mathrm{~Hz})$ & $0.62 \mathrm{~Hz}(0.15 \mathrm{~Hz})$ & $0.64 \mathrm{~Hz}(0.16 \mathrm{~Hz})$ \\
\hline
\end{tabular}

Numbers represent means $( \pm \mathrm{SD})$.

Phase $\mathrm{AE}=$ absolute error of relative phase, Phase $\mathrm{SD}=$ standard deviation of relative phase. 


\section{Results}

\section{Kinematic data}

\section{Relative phase}

Mean values of movement accuracy and stability for both groups are shown in Table 1 . Relative phase $\operatorname{AE}\left(F_{(1,34)}=6.42, p=0.016\right)$ and $\mathrm{SD}\left(F_{(1,34)}=31.94, p=0.001\right)$ were both significantly smaller for the "easy" ISO pattern (main effect of coordination pattern), meaning that the ISO pattern was performed with higher accuracy and with more stability than the NON-ISO pattern. In addition, relative phase SD showed a significant "age group $\times$ coordination pattern" interaction $\left(F_{(1,34)}=7.45, p=0.009\right.$ ) (see Fig. 2). Specifically, whereas in the old group, variability was substantially higher for the NON-ISO compared to the ISO pattern, only moderate differences between patterns were found in the young group.

\section{Movement frequency and amplitude}

Mean values of movement frequency and amplitude for both groups are shown in Table 1 . Movement amplitude was larger for a) older subjects vs. younger subjects $\left(F_{(1,34)}=33.81 p=0.001\right)$ (main effect of group) and $b$ ) performance of the NON-ISO vs. ISO pattern across all subjects $\left(F_{(1,34)}=9.96, p=0.003\right)$ (main effect of coordination pattern). No significant interaction between age group and movement pattern was found. As expected, preferred movement frequency was significantly lower in old subjects $\left(F_{(1,34)}=11.13, p=0.002\right)$. This suggests that the older adults preferred to move slower than the young adults, resulting in higher movement amplitudes. For both groups, no significant frequency differences between the ISO and NON-ISO patterns or between movements with the left or right body side were identified.

\section{fMRI data}

\section{Main effects}

Between group analyses: determining increased brain activations in the elderly

When collapsing across task and body side, older adults recruited a far more elaborate network of motor and non-motor regions than the young (for coordinates see Table 2). In the ipsilateral hemisphere unique activations were found in the ventral premotor cortex (PMv), primary sensorimotor cortex (SM1) (Fig. 3 E) and postcentral gyrus

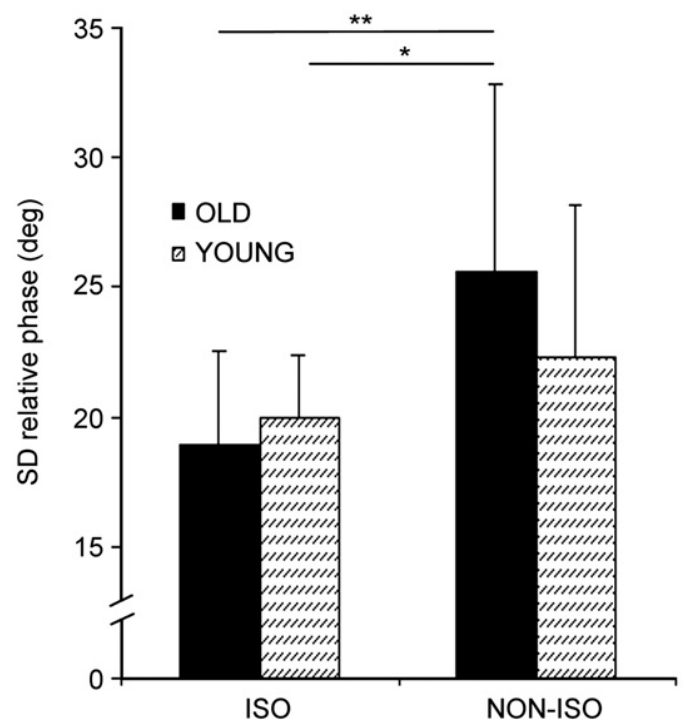

Fig. 2. Standard deviation (SD) of relative phase for both coordination modes, showing a "age group $\times$ coordination pattern" interaction, with post-hoc Tukey corrections. ${ }^{* *} p=0.002,{ }^{*} p=0.011$. Barplots show the mean \pm SD.
Table 2

Brain regions activated for the contrast 'Main effect of group'.

\begin{tabular}{|c|c|c|c|c|c|}
\hline \multirow[t]{2}{*}{ Area } & \multirow[t]{2}{*}{ Side } & \multicolumn{3}{|c|}{ MNI coordinates } & \multirow{2}{*}{$\begin{array}{l}t- \\
\text { value }\end{array}$} \\
\hline & & $\overline{X^{*}}$ & $\mathrm{Y}$ & $\mathrm{Z}$ & \\
\hline \multicolumn{6}{|l|}{ A) Old $>$ young } \\
\hline Inferior frontal gyrus (pars Opercularis) & CL & 56 & 10 & 14 & 3.20 \\
\hline Precentral gyrus (M1) & IL & 38 & -24 & 58 & 4.42 \\
\hline Inferior precentral gyrus (PMv) & IL & 48 & -2 & 32 & 2.99 \\
\hline Postcentral gyrus/central sulcus (SM1) & IL & 48 & -12 & 34 & 3.78 \\
\hline \multirow[t]{2}{*}{ Postcentral gyrus (S1) } & IL & 38 & -38 & 60 & 3.38 \\
\hline & IL & 60 & -10 & 30 & 4.69 \\
\hline \multirow[t]{2}{*}{ Inferior postcentral gyrus (S2) } & IL & 62 & -6 & 22 & 5.15 \\
\hline & $\mathrm{CL}$ & 58 & -22 & 32 & 3.93 \\
\hline Precuneus/paracentral lobule (foot area) & IL & 8 & -50 & 60 & 6.15 \\
\hline Precuneus & $\mathrm{CL}$ & 6 & -52 & 8 & 3.68 \\
\hline Rolandic operculum & $\mathrm{CL}$ & 66 & 4 & 6 & 3.46 \\
\hline Temporal pole & $\mathrm{CL}$ & 62 & 8 & -2 & 3.40 \\
\hline Superior temporal gyrus (OP4) & $\mathrm{CL}$ & 64 & 4 & 2 & 3.45 \\
\hline Superior temporal gyrus (TE 1.0) & $\mathrm{CL}$ & 58 & -14 & -2 & 3.89 \\
\hline Inferior temporal gyrus & $\mathrm{CL}$ & 60 & -62 & -6 & 3.53 \\
\hline Superior parietal gyrus & $\mathrm{CL}$ & 20 & -62 & 60 & 4.49 \\
\hline Supramarginal gyrus & $\mathrm{CL}$ & 54 & -34 & 42 & 3.15 \\
\hline Angular gyrus & $\mathrm{CL}$ & 32 & -58 & 50 & 4.21 \\
\hline Vermis III & M & 2 & -34 & -12 & 3.00 \\
\hline Cerebellum IV-V & IL & 6 & -38 & -8 & 3.30 \\
\hline Cerebellum VI & CL & 8 & -60 & -20 & 4.47 \\
\hline Cerebellar vermis VII & M & 2 & -76 & -24 & 3.58 \\
\hline Cerebellar vermis VIII & M & 6 & -72 & -38 & 3.65 \\
\hline Cerebellum VIII & CL & 16 & -62 & -48 & 3.57 \\
\hline Cerebellum VIII & IL & 4 & -62 & -38 & 3.09 \\
\hline \multicolumn{6}{|l|}{ B) Old $<$ young } \\
\hline Precentral gyrus/central sulcus (M1) & $\mathrm{CL}$ & 36 & -24 & 64 & 7.27 \\
\hline SMA-proper/paracentral lobule & $\mathrm{CL}$ & 10 & -18 & 78 & 6.24 \\
\hline SMA-proper & $\mathrm{CL}$ & 2 & 0 & 48 & 3.69 \\
\hline Rolandic operculum & $\mathrm{CL}$ & 44 & -28 & 18 & 4.18 \\
\hline \multirow[t]{2}{*}{ Putamen } & IL & 26 & 8 & 0 & 3.27 \\
\hline & $\mathrm{CL}$ & 28 & 2 & 4 & 5.13 \\
\hline
\end{tabular}

$t$-values and activation peaks showing significantly ( $p<0,05$; FDR corrected for multiple comparisons) differential activation in A) the old vs. the young group, and B) the young vs. the old group, averaged across movement patterns and body sides. $\mathrm{X}^{*}$ : distance in $\mathrm{mm}$, relative to the interhemispheric fissure. $\mathrm{M} 1=$ primary motor cortex, SM1 = primary sensorimotor cortex, $\mathrm{S} 1(2)=\operatorname{primary}($ secondary) somatosensory cortex, $\mathrm{PMv}=$ ventral premotor cortex, $\mathrm{OP} 4=$ operculum $4, \mathrm{TE} 1.0=$ auditory cortex $\mathrm{CL}=$ contralateral to the moving limbs, $\mathrm{IL}=$ ipsilateral to the moving limbs, $\mathrm{M}=$ midline. The areas in italic were unique for the old group.

(somatosensory area, S1). A large cluster (1726 voxels) in the ipsilateral precuneus extended to the contralateral superior parietal gyrus (Fig. 3E). Within the contralateral hemisphere unique activations were also observed in the angular gyrus and inferior postcentral gyrus (secondary somatosensory area, S2) (Fig. 3D). Activations in the contralateral inferior postcentral gyrus (S2) extended to the contralateral superior temporal gyrus, Rolandic operculum and the inferior frontal gyrus pars opercularis (IFGPO). A smaller cluster was also found in the contralateral inferior temporal gyrus.

In the bilateral anterior and posterior cerebellum (Figs. 3A, B) regions were found that were active in both old and young subjects, but for which the old subjects showed a higher BOLD-response, i.e. age-related overactivation. In a few areas, the old group showed a lower BOLD-response than the younger group (further referred to as age-related underactivation), with peak differences in the contralateral M1, SMA (Fig. 3E), Rolandic operculum and bilateral putamen (Fig. 3C) (for coordinates see Table 2).

\section{Movement of the non-dominant vs. the dominant body side}

When comparing non-dominant vs. dominant body side movements, the largest activation peaks were found in the ipsilateral dorsal premotor cortex (PMd) and SM1 (Fig. 4E) (for coordinates see Table 3). A second peak spread over the contralateral pre-SMA (Fig. 4E). A smaller cluster was also found in the middle cingulate cortex. In addition to these cortical regions, we identified clusters in 


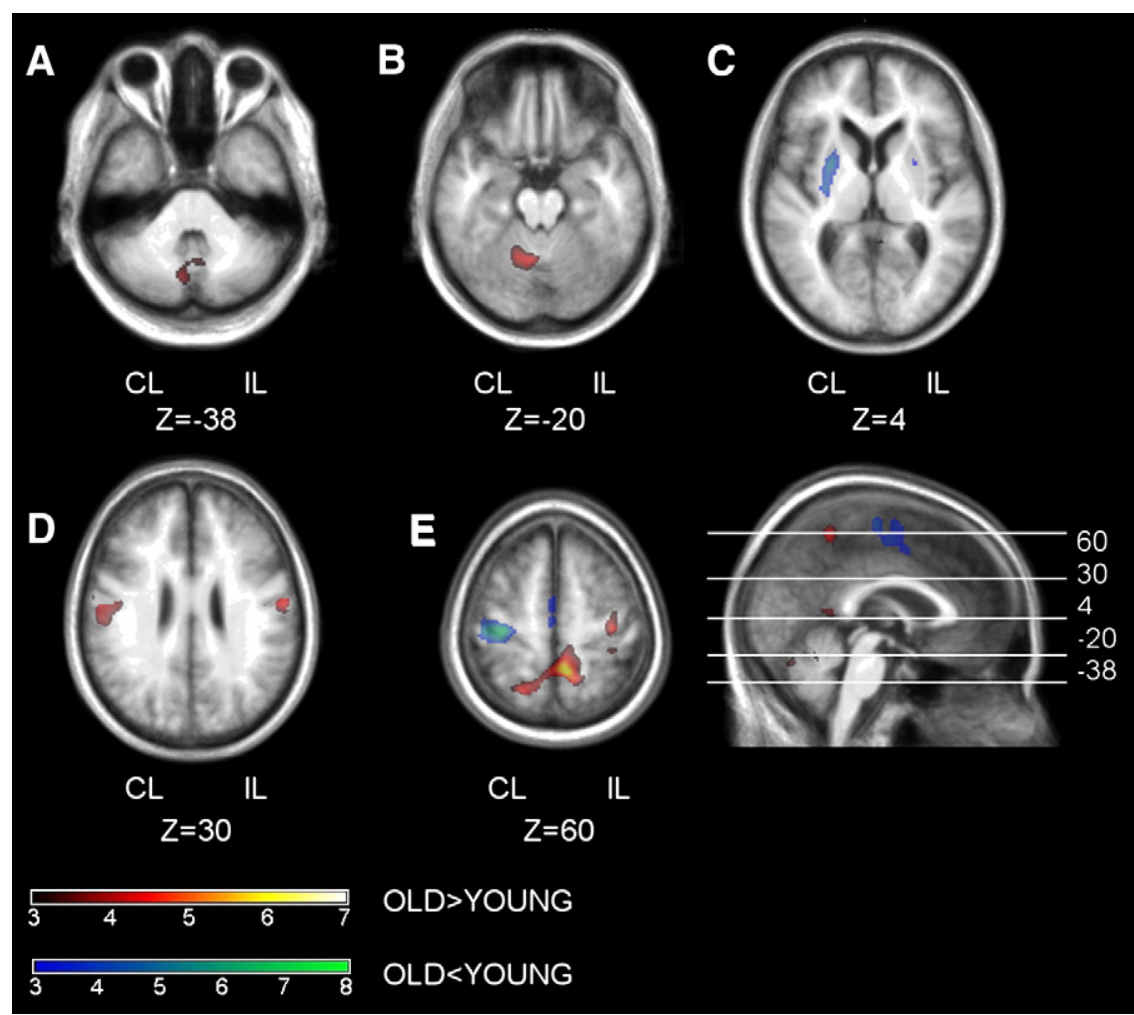

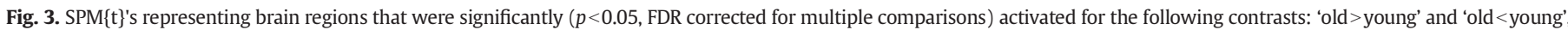
overlaid on transverse sections (A-E) of the average T1 structural scan of the 19 old subjects. $\mathrm{CL}=$ contralateral to the moving limbs, IL $=$ ipsilateral to the moving limbs.

the contralateral anterior and posterior cerebellum, as shown in Figs. 4A-C. Lastly we also found 2 areas that were more active during dominant as opposed to non-dominant body side movements, i.e., contralateral postcentral gyrus and ipsilateral cerebellar lobe VIII (Figs. 4B, D).

The question was asked whether non-dominant body side movements would drive the elderly to recruit even more brain regions. However, a $t$-contrast for the positive "age group $\times$ body side" interaction did not show any significantly activated voxels.

\section{Non-isodirectional vs. isodirectional coordination}

Table 4 shows the list of regions that were more active during performance of the NON-ISO as compared to ISO pattern, when averaged across groups and body sides (i.e., main effect of pattern). No regions were found to be more active during the ISO than during the NON-ISO pattern. Fig. 5 shows that for the more difficult NON-ISO pattern, a more extensive motor network, containing bilateral precentral gyrus (M1 and PMd) (Fig. 5D), bilateral SMA and cingulate cortex (Fig. 5A, B), bilateral superior parietal gyri (Fig. 5D) and contralateral inferior parietal lobule, ipsilateral thalamus and bilateral basal ganglia (Fig. 5B) was recruited. The largest cluster was located subcortically in the bilateral posterior cerebellum (Fig. 5C). We were also interested in age-related increases in brain activity due to task complexity. Therefore we specified a positive "age group $\times$ coordination pattern" interaction in the SPM ANOVA model. This contrast did not reveal any significantly activated regions, neither did the "age group $\times$ body side $\times$ coordination pattern" interaction.

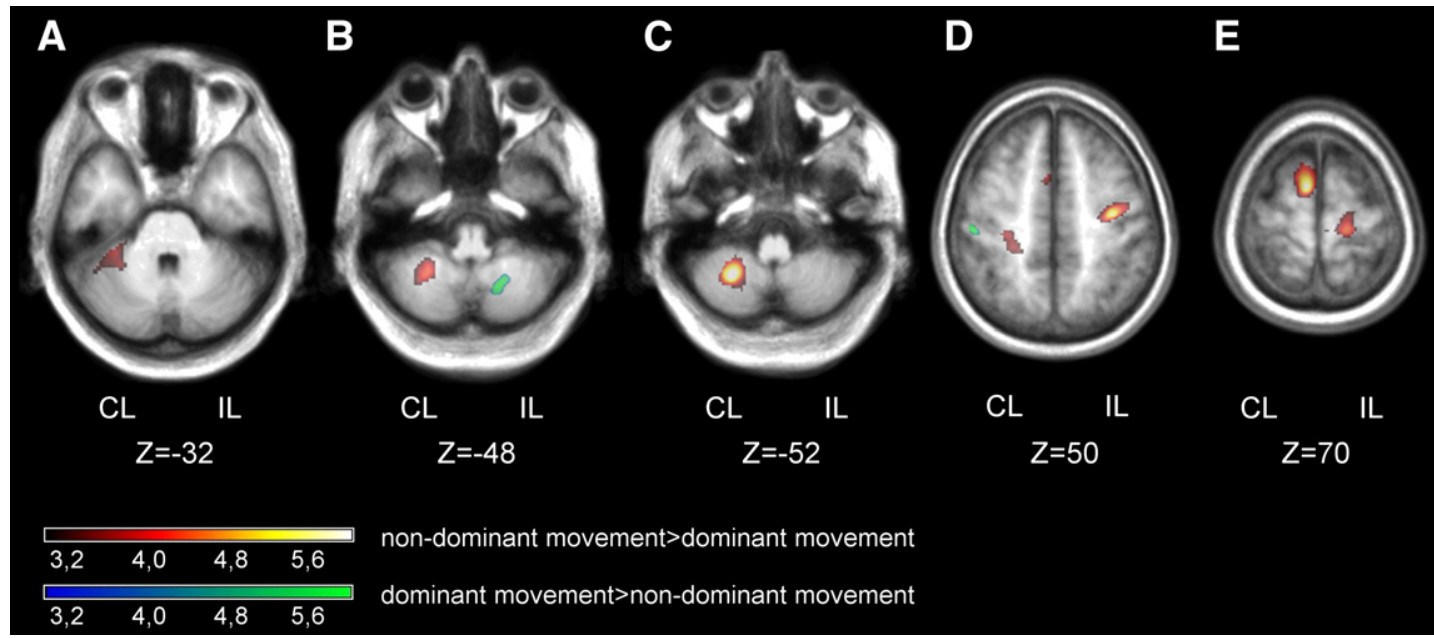

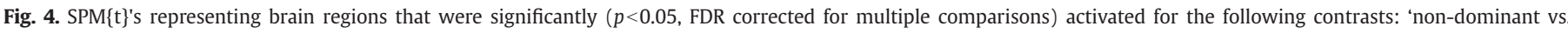

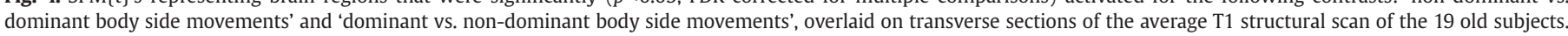
$\mathrm{CL}=$ contralateral to the moving limbs, $\mathrm{IL}=$ ipsilateral to the moving limbs. 
Table 3

Brain regions activated for the contrast 'Main effect of body side'.

\begin{tabular}{|c|c|c|c|c|c|}
\hline \multirow[t]{2}{*}{ Area } & \multirow[t]{2}{*}{ Side } & \multicolumn{3}{|c|}{ MNI coordinates } & \multirow{2}{*}{$\begin{array}{l}t- \\
\text { value }\end{array}$} \\
\hline & & $\overline{X^{*}}$ & $\mathrm{Y}$ & Z & \\
\hline \multicolumn{6}{|c|}{ A) Non-dominant movement $>$ dominant movement } \\
\hline Precentral gyrus (PMd) & IL & 38 & -14 & 52 & 5.89 \\
\hline Precentral gyrus (hand area) & IL & 20 & -18 & 68 & 3.86 \\
\hline Postcentral gyrus (S1) & $\mathrm{IL}$ & 18 & -28 & 72 & 5.00 \\
\hline Postcentral gyrus & $\mathrm{CL}$ & 22 & -36 & 62 & 3.45 \\
\hline Paracentral lobule (foot area) & IL & 6 & -30 & 74 & 3.44 \\
\hline \multirow[t]{2}{*}{ Pre-SMA } & $\mathrm{CL}$ & 8 & 0 & 70 & 6.03 \\
\hline & CL & 4 & 14 & 48 & 3.98 \\
\hline Middle cingulate cortex & $\mathrm{CL}$ & 12 & -8 & 42 & 3.84 \\
\hline Para-hippocampus & $\mathrm{CL}$ & 18 & -26 & -10 & 3.39 \\
\hline Calcarine gyrus & IL & 6 & -56 & 4 & 3.38 \\
\hline \multirow[t]{2}{*}{ Cerebellum crus 1} & $\mathrm{CL}$ & 36 & -62 & -42 & 3.11 \\
\hline & $\mathrm{CL}$ & 44 & -50 & -38 & 4.26 \\
\hline \multirow[t]{2}{*}{ Cerebellum crus 2} & $\mathrm{CL}$ & 16 & -80 & -40 & 3.62 \\
\hline & $\mathrm{CL}$ & 24 & -82 & -36 & 3.22 \\
\hline \multirow[t]{2}{*}{ Cerebellum IV-V } & $\mathrm{CL}$ & 18 & -48 & -14 & 3.53 \\
\hline & $\mathrm{CL}$ & 28 & -30 & -28 & 3.76 \\
\hline \multirow[t]{2}{*}{ Cerebellum VI } & $\mathrm{CL}$ & 34 & -40 & -32 & 3.86 \\
\hline & $\mathrm{CL}$ & 30 & -46 & -32 & 3.62 \\
\hline Cerebellum VIII & $\mathrm{CL}$ & 26 & -54 & -52 & 6.46 \\
\hline \multicolumn{6}{|c|}{ B) Dominant movement $>$ non-dominant movement } \\
\hline Postcentral gyrus & $\mathrm{CL}$ & 52 & -22 & 50 & 5.41 \\
\hline Cerebellum VIII & IL & 18 & -60 & -48 & 5.08 \\
\hline
\end{tabular}

$t$-values and activation peaks showing significantly ( $p<0.05$; FDR corrected for multiple comparisons) larger activation during A) non-dominant vs. dominant movements, and B) during dominant vs. non-dominant movements, averaged across groups and movement patterns. $\mathrm{X}^{*}$ : distance in $\mathrm{mm}$, relative to the interhemispheric fissure. PMd $=$ dorsal premotor cortex, $\mathrm{S} 1$ = primary somatosensory cortex, pre-SMA = pre-supplementary motor area, $\mathrm{CL}=$ contralateral to the moving limbs, $\mathrm{IL}=$ ipsilateral to the moving limbs.

\section{Correlation analysis}

To investigate whether age-related increased activations showed positive associations with coordination performance, a multiple

Table 4

Brain regions activated more during NON-ISO as opposed to ISO coordination.

\begin{tabular}{|c|c|c|c|c|c|}
\hline \multirow[t]{2}{*}{ Area } & \multirow[t]{2}{*}{ Side } & \multicolumn{3}{|c|}{ MNI coordinates } & \multirow{2}{*}{$\begin{array}{l}t- \\
\text { value }\end{array}$} \\
\hline & & $\overline{X^{*}}$ & $\mathrm{Y}$ & $\mathrm{Z}$ & \\
\hline Superior frontal gyrus (PMd) & IL & 20 & -8 & 70 & 5.22 \\
\hline Precentral gyrus (PMd) & IL & 28 & -6 & 56 & 5.65 \\
\hline Precentral gyrus M1 & IL & 30 & -22 & 64 & 2.98 \\
\hline Precentral gyrus (hand area) & CL & 16 & -10 & 66 & 4.75 \\
\hline Postcentral gyrus (S1) & IL & 32 & -34 & 54 & 3.67 \\
\hline \multirow[t]{2}{*}{ SMA-proper } & IL & 8 & -2 & 64 & 4.15 \\
\hline & CL & 10 & -2 & 54 & 3.79 \\
\hline \multirow[t]{2}{*}{ Middle cingulate cortex } & IL & 10 & 6 & 44 & 3.34 \\
\hline & $\mathrm{CL}$ & 10 & 6 & 36 & 3.06 \\
\hline Superior parietal gyrus/postcentral gyrus & IL & 20 & -56 & 64 & 4.66 \\
\hline Superior parietal gyrus & CL & 20 & -58 & 66 & 5.00 \\
\hline Supramarginal gyrus & IL & 36 & -40 & 44 & 3.80 \\
\hline Inferior parietal lobule & CL & 42 & -44 & 44 & 3.22 \\
\hline \multirow[t]{2}{*}{ Thalamus } & IL & 2 & -12 & 8 & 2.85 \\
\hline & IL & 6 & -6 & 4 & 2.64 \\
\hline Putamen & IL & 26 & 6 & 10 & 2.63 \\
\hline \multirow[t]{2}{*}{ Caudate nucleus } & IL & 20 & -16 & 24 & 3.77 \\
\hline & CL & 18 & -16 & 22 & 2.78 \\
\hline \multirow[t]{2}{*}{ Cerebellum VI } & CL & 32 & -44 & -32 & 4.79 \\
\hline & IL & 34 & -50 & -34 & 4.51 \\
\hline Cerebellar vermis VI & M & 2 & -60 & -20 & 6.46 \\
\hline \multirow[t]{2}{*}{ Cerebellum VIII } & IL & 26 & -60 & -48 & 4.54 \\
\hline & $\mathrm{CL}$ & 28 & -54 & -50 & 5.31 \\
\hline Cerebellar vermis VIII & M & 0 & -70 & -34 & 6.56 \\
\hline
\end{tabular}

$t$-values and activation peaks showing significantly ( $p<0.05$; FDR corrected for multiple comparisons) larger activation during the execution of the NON-ISO pattern as opposed to the ISO pattern, averaged across groups and body sides. $\mathrm{X}^{*}$ : distance in $\mathrm{mm}$, relative to the interhemispheric fissure. PMd = dorsal premotor cortex, M1 = primary motor cortex, $\mathrm{S} 1$ = primary somatosensory cortex, $\mathrm{CL}=$ contralateral to the moving limbs, $\mathrm{IL}=$ ipsilateral to the moving limbs, $\mathrm{M}=$ midline.

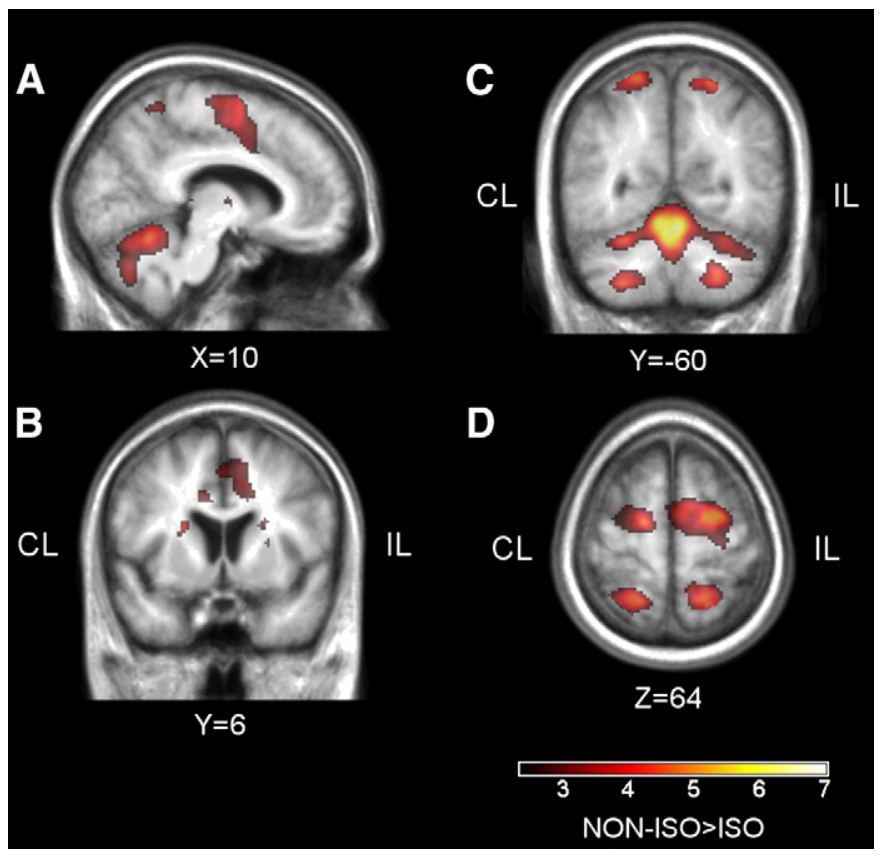

Fig. 5. $\operatorname{SPM}\{\mathrm{t}\}$ 's representing brain regions that were significantly $(p<0.05$, FDR corrected for multiple comparisons) activated for the following contrast: 'NONISO > ISO'. overlaid on sagittal (A), coronal (B, C) and transverse (D) sections of the average $\mathrm{T} 1$ structural scan of the 19 old subjects $\mathrm{CL}=$ contralateral to the moving limbs, $\mathrm{IL}=$ ipsilateral to the moving limbs.

regression analysis was performed on the first-level contrast images of the elderly. For each condition: left ISO, left NON-ISO, right ISO and right NON-ISO, an SPM model was defined, containing the performance level and the age of each individual as a covariate. AE of relative phase $\left(\mathrm{AE}^{-1}\right)$ was used as a measure for performance in accordance with Heuninckx et al. (2008).

Clusters that were more active for 1 ) young vs. old subjects or 2) old vs. young subjects, thresholded at $p<0.05$ (FDR corrected), were used as an explicit mask. When thresholded at $p<0.001$ (uncorrected), no regions were found to correlate either positively or negatively with motor performance. When using SD of relative phase, similar results were obtained. This is not surprising because AE and SD measures were highly correlated (Pearson $r=0.80$ and $r=0.87$ for ISO and NON-ISO, respectively). These results are in contrast to previous work identifying positive correlations during NON-ISO coordination of the dominant limb at an imposed pace (Heuninckx et al., 2008). We assume that allowing the elderly to select a comfort pacing compromised the search for positive associations between performance and increased brain activation.

\section{Discussion}

Here, we investigated the age-related neural correlates of performing ipsilateral hand-foot movements of varying difficulty. We extended our previous work (Heuninckx et al., 2005, 2008) by investigating movement at preferred rate with the non-dominant as opposed to the dominant body side and explored the degree of ipsilateral brain activation during these conditions. Even though movements were performed at comfort rate, older adults still showed increased recruitment of neural resources in contralateral and ipsilateral regions, reflecting increased deployment of attention and more pronounced processing of somatosensory information. This effect was not mediated by coordination complexity or body side. In addition, some motor regions showed underactivation in the elderly (i.e. contralateral M1, SMA and the putamen). The obtained effects will be discussed in more detail next. 
Age-related increased activations reflect enhanced attention-to-action and proprioceptive guidance

Unique ipsilateral activity was observed in PMv and SM1 in elderly as compared to young adults. No mirror movements were observed that could account for such activity. PMv has already been found to be active during complex bimanual as well as ipsilateral interlimb coordination tasks (Debaere et al., 2004a; Heuninckx et al., 2005). The SM1 findings are in agreement with previous work showing that the deactivation of ipsilateral M1 observed in young subjects (Newton et al., 2005) is reduced with advancing age (Ward et al., 2008; Ward and Frackowiak, 2003) resulting in relative overactivation (Hutchinson et al., 2002; Mattay et al., 2002; Naccarato et al., 2006).

There is still controversy concerning the functional role of ipsilateral M1 during unilateral movements. Age-related recruitment of this area could be due to decreased interhemispheric inhibition (IHI), caused by degeneration of callosal fibres. Diffusion Tensor Imaging (DTI) studies have already shown that 1) with aging, the fractional anisotropy (FA) of the corpus callosum decreases (Sullivan and Pfefferbaum, 2006) and that 2) the FA-value of the hand callosal motor fibres positively correlates with IHI, as assessed by paired-pulse transcranial magnetic stimulation (TMS) (Wahl et al., 2007). Additionally, intracortical inhibitory M1 circuits are less excitable in older adults (Peinemann et al., 2001), potentially increasing the susceptibility of this region to intra- or interhemispheric input.

In addition to the aforementioned ipsilateral brain areas, unique activations were also seen in the bilateral anterior precuneus, contralateral superior and inferior parietal lobe and contralateral S2. Activation in the anterior precuneus has been shown in previous aging research. This region is involved in top down control of attention (Cavanna and Trimble, 2006; Schwartz et al., 2004). Together with the precuneus, recruitment of the superior parietal lobe may have been a consequence of the spatial task requirements, more specifically, the directional relationships between both moving limb segments. Wenderoth et al. (2005) found bilateral activations in the superior parietal lobe, within $4 \mathrm{~mm}$ distance of our location, that were ascribed to shifts of attention in extrinsic space. In the context of this study, this might indicate that the elderly switched attention between their hand and foot. We also found activations in the contralateral supramarginal and angular gyrus, areas known to be involved in higher-level monitoring of motor plans and in so-called action awareness, i.e. the discrepancy between intended and actual movements (Farrer et al., 2003). We hypothesize that older subjects monitored their actions more carefully to maintain the required spatiotemporal relationship between the limbs.

Age-related overactivations were observed in the bilateral anterior and posterior cerebellum. Whereas anterior cerebellum activation is very common across many motor tasks, activations in the posterior cerebellum are often observed when performing interlimb coordination and other motor tasks under cognitively more demanding conditions (Debaere et al., 2004b; Wenderoth et al., 2004). The posterior cerebellar region is linked to motor timing based on sensory feedback, as shown by studies in cerebellar patients (Ivry, 1997). Our activation peak $[16,-62,-48]$ in lobule VIII also suggests a somatosensory function, as it is in close proximity of the peak response $[18,-62,-46]$ to tactile matching tasks reported by Stoodley and Schmahmann (2009). The observed cerebellar activations are complementary to those in S1 and S2, suggesting that the older adults made use of a more pronounced processing and integration of proprioceptive feedback arising from two distant limb segments. This may also reflect compensation for peripheral decline, e.g. decreased muscle spindle sensitivity (Goble et al., 2009).

Age-related underactivation of the motor network

Reduced brain activation as a result of aging is seldom reported for fMRI studies on motor control (for exceptions see Hutchinson et al.,
2002; Riecker et al., 2006, Wu and Hallett, 2005). This is an equally meaningful result because some age-related motor pathologies (e.g. Parkinson's disease) show reduced activations in particular brain regions (e.g., the basal ganglia). Interestingly, the old group showed significantly lower activations than the young group in contralateral M1, SMA and bilateral putamen, when moving at lower frequency ( $0.63 \mathrm{~Hz}$ in the old vs. $0.84 \mathrm{~Hz}$ in the young group). The former 2 regions are known to be involved in frequency modulation. However, it has been demonstrated that the linear relation between the BOLDresponse and movement frequency only holds true for frequencies above $1 \mathrm{~Hz}$ (Jäncke et al., 1998; Sadato et al., 1996; Van Meter et al., 1995). Therefore, we propose that the lower comfort pace in the elderly could not have accounted for the observed age-related underactivation in contralateral M1 and SMA.

There have been some conflicting results concerning age-related contralateral M1 activity. Hutchinson et al. (2002), Riecker et al. (2006) and Wu and Hallett (2005) found age-related decreases in contralateral M1 activity, consistent with our results. Other groups however found no changes (Calautti et al., 2001; Daselaar et al., 2003; Ward and Frackowiak, 2003), or showed age-related overactivity in contralateral SM1 (Mattay et al., 2002). Different task paradigms and movement speeds compromise comparisons among studies. TMS studies have reported decreased M1 excitability with aging (Oliviero et al., 2006). Although this seems to support our M1 observations, further research is needed.

Underactivation of putamen by the older adults is in contrast with some previous findings (Mattay et al., 2002; Ward et al., 2008). Decreased activation of the putamen could have caused SMA underactivation through the direct striatothalamocortical pathway. Similarly, reduced activation in the SMA and putamen has been observed in patients with Parkinson's disease (Yu et al., 2007). Loss of dopaminergic neurons in the substantia nigra, causes dopamine deficiencies in the "motor loop" of the basal ganglia, leading to bradykinesia. Although the elderly subjects in this study showed no Parkinson like symptoms, they may have incurred a dopamine decline. PET and SPECT studies have already shown a reduced availability of D1- and D2-like receptors (Bäckman et al., 2000; Rinne et al., 1993; Wang et al., 1998) and dopamine transporters (Volkow et al., 1998) in the striatum during healthy aging.

\section{Evidence for bilateral activations during movements of the non-dominant body side}

No behavioral differences were observed between movements with the left as opposed to the right body side. However, fMRI data showed that movements with the non-dominant body side were associated with a more extended network of motor regions, with more ipsilateral cortical and more contralateral cerebellar activation. This indicates that a differential neural effort was required to perform at the same level as the dominant limbs. Although this contrast was averaged across both groups (main effect), the present findings comply with studies in adolescents (Rogers et al., 2004; van Mier et al., 1998; Verstynen et al., 2005). Non-dominant limb movement induced bilateral activation in the basic motor network (SM1, SMA, cingulate cortex, and cerebellum). Higher activation in ipsilateral M1 was seen, implying that the left M1 was more active for left limb movements than the right M1 was active for right limb movements. This is in agreement with previous studies suggesting that left M1 has a greater transcallosal inhibitory effect over right M1, than vice versa (Haaland and Harrington, 1996; Hayashi et al., 2008).

The observed activation in the ipsilateral PMd and contralateral pre-SMA suggests that higher cognitive demands and more pronounced movement preparation were required when moving the left body side. This is further supported by the activity observed in the lateral cerebellum which is connected with the prefrontal cortex, and has been assigned with a more cognitive role, especially in non-motor 
tasks that involve attention and executive control (Ramnani, 2006). Our activations were at the border of contralateral cerebellar Crus 1 and Crus $2[36,-62,-42]$, and closely matched activation peaks [34, $-64,-34$ ] observed in working memory research (Stoodley and Schmahmann, 2009). This highlights a seemingly increased cognitive load of left body side movements.

In contrast to our hypothesis but in agreement with Calautti et al. (2001) and Ward and Frackowiak (2003), we did not find significant age-related activation differences between movements of the nondominant vs. dominant limb segments ("age group $\times$ body side" interaction). This could be due to limited statistical power, even though our sample size was quite large. Alternatively, this may imply that the older adults already approached the upper limits of their neural resources when moving their dominant limbs.

\section{Non-isodirectional vs. isodirectional ipsilateral coordination}

In accordance with previous behavioural work, our kinematic data showed that the NON-ISO coordination pattern was performed with less accuracy and stability than the ISO pattern (Baldissera et al., 1982; Carson et al., 1995; Heuninckx et al., 2005; Rocca et al., 2007). This behavioral distinction has been corroborated by medical imaging research in young subjects, showing a more extensive brain activation network during NON-ISO than ISO coordination (Caeyenberghs et al., 2009; Debaere et al., 2001; Rocca et al., 2007). Our data were averaged across old and young subjects, but they are in general agreement with previous work.

NON-ISO coordination required a higher activation in the distributed motor network consisting of SM1, PMd, SMA, cingulate cortex, parietal lobes, thalamus, putamen, caudate and cerebellum. Overall, this suggests that higher planning effort and increased error monitoring were needed to comply with the more stringent spatial requirements of the NON-ISO pattern and to suppress the intrinsically favored ISO pattern.

Contrary to our a priori hypothesis, we did not observe an "age $\times$ coordination pattern" or an "age $\times$ body side $\times$ coordination pattern" interaction. Heuninckx et al. (2005) however, used the same coordination task as we did, and found a network of prefrontal, precentral, parietal, occipital, and cerebellar regions showing higher activations for NON-ISO vs. ISO in older as compared to younger groups, when moving the dominant body side. The activations they observed can most likely be accounted for by the higher speed requirements $(1 \mathrm{~Hz})$ via enforced metronome pacing, making the NON-ISO even more challenging for the elderly to perform. In the present study, elderly participants were allowed to self-select their movement rate $(0.63 \mathrm{~Hz})$.

\section{Conclusions}

When performing the ipsilateral coordination patterns at comfort pacing, healthy old as compared to young subjects still showed unique activation in brain areas related to sensory processing and intrasensory integration of both limb segments. In addition, they exhibited more elaborate attentional deployment to support the spatial requirements of ipsilateral coordination. The increased activation possibly reflects how elderly participants cope with behavioral and neural declines to secure success in performance. The lack of significant interaction effects suggests that elderly individuals did not recruit additional brain areas during performance of more complex coordination tasks and/or movements with the non-dominant body side, on top of the "basic" additional activations displayed by young individuals. Functional declines and an altered neural strategy may have limited the capacity of elderly individuals to modulate neural effects. Alternatively, performing movements at comfort pacing may not have triggered neural modulation sufficiently. Future research is warranted to further assess the limits of age-related brain activity modulation as a function of different task features.

\section{Acknowledgments}

Support for this study was provided through a grant from the Research Council of K.U.Leuven, Belgium (Contract OT/07/73) and the Research Programme of the Research Foundation - Flanders (FWO, \# G.0593.08). This work was also supported by Grant P6/29 from the Interuniversity Attraction Poles program of the Belgian federal government.

\section{References}

Andersson, J.L., Hutton, C., Ashburner, J., Turner, R., Friston, K., 2001. Modeling geometric deformations in EPI time series. NeuroImage 13, 903-919.

Bäckman, L., Ginovart, N., Dixon, R.A., Wahlin, T.B., Wahlin, A., Halldin, C., Farde, L., 2000. Age-related cognitive deficits mediated by changes in the striatal dopamine system. Am. J. Psychiatry 157, 635-637.

Baldissera, F., Cavallari, P., Civaschi, P., 1982. Preferential coupling between voluntary movements of ipsilateral limbs. Neurosci. Lett. 34, 95-100.

Cabeza, R., 2002. Hemispheric asymmetry reduction in older adults: the HAROLD model. Psychol. Aging 17, 85-100.

Cabeza, R., Nyberg, L., Park, D.C., 2005. Cognitive Neuroscience of Aging. Oxford Univ. Press, New York.

Caeyenberghs, K., Wenderoth, N., Smits-Engelsman, B.C. Sunaert, S., Swinnen, S.P. 2009. Neural correlates of motor dysfunction in children with traumatic brain injury: exploration of compensatory recruitment patterns. Brain 132, 684-694.

Calautti, C., Serrati, C., Baron, J.C., 2001. Effects of age on brain activation during auditory-cued thumb-to-index opposition: a positron emission tomography study. Stroke 32, 139-146.

Carson, R.G., Goodman, D., Kelso, J.A., Elliott, D., 1995. Phase transitions and critical fluctuations in rhythmic coordination of ipsilateral hand and foot. J. Mot. Behav. 27, 211-224.

Cavanna, A.E., Trimble, M.R., 2006. The precuneus: a review of its functional anatomy and behavioural correlates. Brain 129, 564-583.

Daselaar, S.M., Rombouts, S.A., Veltman, D.J., Raaijmakers, J.G., Jonker, C., 2003. Similar network activated by young and old adults during the acquisition of a motor sequence. Neurobiol. Aging 24, 1013-1019.

Debaere, F., Swinnen, S.P., Beatse, E., Sunaert, S., Van, H.P., Duysens, J., 2001. Brain areas involved in interlimb coordination: a distributed network. Neurolmage 14, 947-958.

Debaere, F., Wenderoth, N., Sunaert, S., Van Hecke, P., Swinnen, S.P., 2004a. Changes in brain activation during the acquisition of a new bimanual coordination task. Neuropsychologia 42, 855-867.

Debaere, F., Wenderoth, N., Sunaert, S., Van Hecke, P., Swinnen, S.P., 2004b. Cerebellar and premotor function in bimanual coordination: parametric neural responses to spatiotemporal complexity and cycling frequency. Neurolmage 21, 1416-1427.

Duvernoy, HM, 1999. The Human Brain: Surface, Three-Dimensional Sectional Anatomy with MRI, and Blood Supply, 2nd ed. Springer-Verlag, New York.

Eickhoff, S.B., Stephan, K.E., Mohlberg, H., Grefkes, C., Fink, G.R., Amunts, K., Zilles, K., 2005. A new SPM toolbox for combining probabilistic cytoarchitectonic maps and functional imaging data. NeuroImage 25, 1325-1335.

Farrer, C., Franck, N., Georgieff, N., Frith, C.D., Decety, J., Jeannerod, M., 2003. Modulating the experience of agency: a positron emission tomography study. Neurolmage 18 , 324-333.

Folstein, M.F., Folstein, S.E., McHugh, P.R., 1975. "Mini-mental state”. A practical method for grading the cognitive state of patients for the clinician. J. Psychiatr. Res. 12, 189-198.

Friston, K.J., Holmes, A.P., Poline, J.B., Grasby, P.J., Williams, S.C., Frackowiak, R.S., Turner, R., 1995a. Analysis of fMRI time-series revisited. NeuroImage 2, 45-53.

Friston, K., Holmes, A., Worsley, K., Poline, J., Frith, C., Frackowiak, R., 1995b. Statistical parametric maps in functional imaging: a general linear approach. Hum. Brain Mapp. 2, 189-210.

Goble, D.J., Coxon, J.P., Wenderoth, N., Van Impe, A., Swinnen, S.P., 2009. Proprioceptive sensibility in the elderly: degeneration, functional consequences and plasticadaptive processes. Neurosci. Biobehav. Rev. 33, 271-278.

Good, C.D., Johnsrude, I.S., Ashburner, J., Henson, R.N., Friston, K.J., Frackowiak, R.S., 2001. A voxel-based morphometric study of ageing in 465 normal adult human brains. Neurolmage 14, 21-36.

Haaland, K.Y., Harrington, D.L., 1996. Hemispheric asymmetry of movement. Curr. Opin. Neurobiol. 6, 796-800.

Hayashi, M.J., Saito, D.N., Aramaki, Y., Asai, T., Fujibayashi, Y., Sadato, N., 2008. Hemispheric asymmetry of frequency-dependent suppression in the ipsilateral primary motor cortex during finger movement: a functional magnetic resonance imaging study. Cereb. Cortex 18, 2932-2940.

Heuninckx, S., Wenderoth, N., Debaere, F., Peeters, R., Swinnen, S.P., 2005. Neural basis of aging: the penetration of cognition into action control. J. Neurosci. 25, 6787-6796.

Heuninckx, S., Wenderoth, N., Swinnen, S.P., 2008. Systems neuroplasticity in the aging brain: recruiting additional neural resources for successful motor performance in elderly persons. J. Neurosci. 28, 91-99. 
Hutchinson, S., Kobayashi, M., Horkan, C.M., Pascual-Leone, A., Alexander, M.P., Schlaug G., 2002. Age-related differences in movement representation. Neurolmage 17, $1720-1728$.

Ivry, R., 1997. Cerebellar timing systems. Int. Rev. Neurobiol. 41, 555-573.

Jäncke, L., Specht, K., Mirzazade, S., Loose, R., Himmelbach, M., Lutz, K., Shah, N.J., 1998. A parametric analysis of the 'rate effect' in the sensorimotor cortex: a functional magnetic resonance imaging analysis in human subjects. Neurosci. Lett 252, 37-40.

Kapreli, E., Athanasopoulos, S., Papathanasiou, M., Van, H.P., Strimpakos, N., Gouliamos, A., Peeters, R., Sunaert, S., 2006. Lateralization of brain activity during lower limb joints movement. An fMRI study. NeuroImage 32, 1709-1721.

Kelso, J.A., Scholz, J.P., Schoner, G., 1986. Nonequilibrium phase-transitions in coordinated biological motion - critical fluctuations. Phys. Lett. A 118, 279-284.

Kim, S.G., Ashe, J., Hendrich, K., Ellermann, J.M., Merkle, H., Ugurbil, K., Georgopoulos, A. P., 1993. Functional magnetic resonance imaging of motor cortex: hemispheric asymmetry and handedness. Science 261, 615-617.

Mattay, V.S., Callicott, J.H., Bertolino, A., Santha, A.K., Van Horn, J.D., Tallent, K.A., Frank, J. A., Weinberger, D.R., 1998. Hemispheric control of motor function: a whole brain echo planar fMRI study. Psychiatry Res. 83, 7-22.

Mattay, V.S., Fera, F., Tessitore, A., Hariri, A.R., Das, S., Callicott, J.H., Weinberger, D.R., 2002. Neurophysiological correlates of age-related changes in human motor function. Neurology 58, 630-635.

Naccarato, M., Calautti, C., Jones, P.S., Day, D.J., Carpenter, T.A., Baron, J.C., 2006. Does healthy aging affect the hemispheric activation balance during paced index-tothumb opposition task? An fMRI study. NeuroImage 32, 1250-1256.

Newton, J.M., Sunderland, A., Gowland, P.A., 2005. fMRI signal decreases in ipsilateral primary motor cortex during unilateral hand movements are related to duration and side of movement. Neurolmage 24, 1080-1087.

Nirkko, A.C., Ozdoba, C., Redmond, S.M., Burki, M., Schroth, G., Hess, C.W., Wiesendanger, M., 2001. Different ipsilateral representations for distal and proximal movements in the sensorimotor cortex: activation and deactivation patterns. NeuroImage 13, 825-835.

Oldfield, R.C., 1971. The assessment and analysis of handedness: the Edinburgh inventory. Neuropsychologia 9, 97-113.

Oliviero, A., Profice, P., Tonali, P.A., Pilato, F., Saturno, E., Dileone, M., Ranieri, F., Di, L., V, 2006. Effects of aging on motor cortex excitability. Neurosci. Res. 55, 74-77.

Peinemann, A., Lehner, C., Conrad, B., Siebner, H.R., 2001. Age-related decrease in paired-pulse intracortical inhibition in the human primary motor cortex. Neurosci. Lett. 313, 33-36.

Ramnani, N., 2006. The primate cortico-cerebellar system: anatomy and function. Nat. Rev., Neurosci. 7, 511-522.

Reuter-Lorenz, P.A., Lustig, C., 2005. Brain aging: reorganizing discoveries about the aging mind. Curr. Opin. Neurobiol. 15, 245-251.

Riecker, A., Groschel, K., Ackermann, H., Steinbrink, C., Witte, O., Kastrup, A., 2006. Functional significance of age-related differences in motor activation patterns. Neurolmage 32, 1345-1354.

Rinne, J.O., Hietala, J., Ruotsalainen, U., Sako, E., Laihinen, A., Nagren, K., Lehikoinen, P., Oikonen, V., Syvalahti, E., 1993. Decrease in human striatal dopamine D2 receptor density with age: a PET study with [11C]raclopride. J. Cereb. Blood Flow Metab. 13, 310-314.

Rocca, M.A., Gatti, R., Agosta, F., Tortorella, P., Riboldi, E., Broglia, P., Filippi, M., 2007. Influence of body segment position during in-phase and antiphase hand and foot movements: a kinematic and functional MRI study. Hum. Brain Mapp. 28, 218-227.

Rogers, B.P., Carew, J.D., Meyerand, M.E., 2004. Hemispheric asymmetry in supplementary motor area connectivity during unilateral finger movements. NeuroImage 22, 855-859.
Rowe, J.B., Siebner, H., Filipovic, S.R., Cordivari, C., Gerschlager, W., Rothwell, J. Frackowiak, R., 2006. Aging is associated with contrasting changes in local and distant cortical connectivity in the human motor system. NeuroImage 32 $747-760$.

Sadato, N., Ibanez, V., Deiber, M.P., Campbell, G., Leonardo, M., Hallett, M., 1996. Frequency-dependent changes of regional cerebral blood flow during finger movements. J. Cereb. Blood Flow Metab. 16, 23-33.

Schwartz, A.B., Moran, D.W., Reina, G.A., 2004. Differential representation of perception and action in the frontal cortex. Science 303, 380-383.

Spirduso, W.W., MacRae, P.G., 1990. Motor Performance and Aging. Handbook of the Psychology of Aging, 3 ed, pp. 183-200.

Stewart, A.L., Mills, K.M., King, A.C., Haskell, W.L., Gillis, D., Ritter, P.L., 2001. CHAMPS physical activity questionnaire for older adults: outcomes for interventions. Med. Sci. Sports Exerc. 33, 1126-1141.

Stoodley, C.J., Schmahmann, J.D., 2009. Functional topography in the human cerebellum: a meta-analysis of neuroimaging studies. Neurolmage 44, 489-501.

Sullivan, E.V., Pfefferbaum, A., 2006. Diffusion tensor imaging and aging. Neurosci Biobehav. Rev. 30, 749-761.

Van Meter, J.W., Maisog, J.M., Zeffiro, T.A., Hallett, M., Herscovitch, P., Rapoport, S.I., 1995 Parametric analysis of functional neuroimages: application to a variable-rate motor task. NeuroImage 2, 273-283.

van Mier, H., Tempel, L.W., Perlmutter, J.S., Raichle, M.E., Petersen, S.E., 1998. Changes in brain activity during motor learning measured with PET: effects of hand of performance and practice. J. Neurophysiol. 80, 2177-2199.

Verstynen, T., Diedrichsen, J., Albert, N., Aparicio, P., Ivry, R.B., 2005. Ipsilateral motor cortex activity during unimanual hand movements relates to task complexity. J. Neurophysiol. 93, 1209-1222.

Volkow, N.D., Fowler, J.S., Ding, Y.S., Wang, G.J., Gatley, S.J., 1998. Positron emission tomography radioligands for dopamine transporters and studies in human and nonhuman primates. Adv. Pharmacol. 42, 211-214.

Wahl, M., Lauterbach-Soon, B., Hattingen, E., Jung, P., Singer, O., Volz, S., Klein, J.C., Steinmetz, H., Ziemann, U., 2007. Human motor corpus callosum: topography, somatotopy, and link between microstructure and function. J. Neurosci. 27, 12132-12138.

Wang, Y., Chan, G.L., Holden, J.E., Dobko, T., Mak, E., Schulzer, M., Huser, J.M., Snow, B.J., Ruth, T.J., Calne, D.B., Stoessl, A.J., 1998. Age-dependent decline of dopamine D1 receptors in human brain: a PET study. Synapse 30, 56-61.

Ward, N.S., 2006. Compensatory mechanisms in the aging motor system. Ageing Res. Rev. 5, 239-254.

Ward, N.S., Frackowiak, R.S., 2003. Age-related changes in the neural correlates of motor performance. Brain 126, 873-888.

Ward, N.S., Swayne, O.B., Newton, J.M., 2008. Age-dependent changes in the neura correlates of force modulation: an fMRI study. Neurobiol. Aging 29, 1434-1446.

Wenderoth, N., Debaere, F., Swinnen, S.P., 2004. Neural networks involved in cyclical interlimb coordination as revealed by medical imaging techniques. In: Swinnen, S.P., Duysens, J. (Eds.), Neuro-Behavioral Determinants of Interlimb Coordination: A Multidisciplinary Approach. Kluwer Academic Publishers, Boston/Dordrecht/ London, pp. 127-222.

Wenderoth, N., Debaere, F., Sunaert, S., Swinnen, S.P., 2005. The role of anterior cingulate cortex and precuneus in the coordination of motor behaviour. Eur. J. Neurosci. 22, 235-246.

$\mathrm{Wu}, \mathrm{T}$., Hallett, M., 2005. The influence of normal human ageing on automatic movements. J. Physiol. 562, 605-615.

Yu, H., Sternad, D., Corcos, D.M., Vaillancourt, D.E., 2007. Role of hyperactive cerebellum and motor cortex in Parkinson's disease. NeuroImage 35, 222-233. 